\title{
Coordination and control in project-based work: digital objects and infrastructures for delivery
}

Article

Accepted Version

Whyte, J. and Lobo, S. (2010) Coordination and control in project-based work: digital objects and infrastructures for delivery. Construction Management and Economics, 28 (6). pp. 557-567. ISSN 0144-6193 doi:

https://doi.org/10.1080/01446193.2010.486838 Available at https://centaur.reading.ac.uk/17268/

It is advisable to refer to the publisher's version if you intend to cite from the work. See Guidance on citing.

To link to this article DOI: http://dx.doi.org/10.1080/01446193.2010.486838

Publisher: Taylor \& Francis

All outputs in CentAUR are protected by Intellectual Property Rights law, including copyright law. Copyright and IPR is retained by the creators or other copyright holders. Terms and conditions for use of this material are defined in the End User Agreement.

www.reading.ac.uk/centaur 
Central Archive at the University of Reading

Reading's research outputs online 


\title{
Coordination and control in project-based work: digital objects and infrastructures for delivery
}

\author{
Published version:
}

Whyte, J. \& Lobo, S. (2010) Coordination and control in project-based work: digital objects and infrastructures for delivery. Construction Management and Economics 28(6): 557-567.

The final, definitive version of this paper has been published in Construction Management and Economics, 28/06, 2010 by Taylor and Francis Ltd, All rights reserved. (C) This is the accepted version, posted by the first author on the University of Reading website under the terms of the contributor agreement. Please cite the published version and refer to it for pages, etc.

\begin{abstract}
A major infrastructure project is used to investigate the role of digital objects in the coordination of engineering design work. From a practice-based perspective, research emphasises objects as important in enabling cooperative knowledge work and knowledge sharing. The term 'boundary object' has become used in the analysis of mutual and reciprocal knowledge sharing around physical and digital objects. The aim is to extend this work by analysing the introduction of an extranet into the public-private partnership project used to construct a new motorway. Multiple categories of digital objects are mobilised in coordination across heterogeneous, cross-organizational groups. The main findings are that digital objects provide mechanisms for accountability and control, as well as for mutual and reciprocal knowledge sharing; and that different types of objects are nested, forming a digital infrastructure for project delivery. Reconceptualising boundary objects as a digital infrastructure for delivery has practical implications for management practices on large projects and for the use of digital tools, such as building information models, in construction. It provides a starting point for future research into the changing nature of digitally-enabled coordination in project-based work.
\end{abstract}

\section{Introduction}

Recent work by organizational scholars articulates the situated practices involved in everyday knowledge work, in fields such as technology use (e.g. Orlikowski 2007); operational safety (e.g. Gherardi and Nicolini 2000) and strategy development (e.g. Jarzabkowski and Seidl 2008). These trajectories of research challenge descriptions of organization as purely social, arguing instead that it is socio-material in nature. Hence, they focus attention on how organizing is achieved through interactions between people and objects in specific places and times. From this perspective, rich empirically-grounded analyses of particular types of organizing have greater validity than theoretical generalizations about 'organization' in the abstract.

Projects to deliver new buildings and infrastructure are a rich context for analyses of the role of objects and their use in knowledge sharing and knowledge transformation. They increasingly involve an array of digital objects, such as building information models (Erdogan et al. 2008, Fischer and Drogemuller 2009). New forms of innovation have been observed through attention to the interactions between people and digital objects (Harty 2005, Boland, Lyytinen and Yoo 2007, Taylor 2007, Forgues, Koskela and Lejeune 2009). New contractual forms, such as public private partnerships, make construction projects increasingly complex organizational settings 
(Van Marrewijk et al. 2008). They provide an interesting site in which to examine how digital objects are implicated, not only in innovation, but also more generally in coordination and delivery. The importance of such work is recognised in construction, as researchers interested in building information models shift their focus from technology to: "the manner in which behaviour will change as collaboration and communication are enhanced" (Shen, Brandon and Baldwin 2009: p. 1).

There are a number of approaches to theorising interactions between objects and work practices in the wider literatures, but it is the concept of a 'boundary object' that has attracted the most attention $^{2}$. The term was first used, not in research on design and engineering, but in a study of work practices within a research museum (Star and Griesemer 1989). It was introduced to explain cooperation in local interactions. A range of objects, such as a questionnaire sheet, stuffed owl or map of California, were observed to enable mutual cooperation and knowledge sharing across diverse knowledge-bases and levels of expertise towards the goal of recording information for posterity and preservation.

For Star and Griesemer the translations that are required in cooperation to meet the scientific goals of the museum involve methods to discipline information and objects that maximize both the autonomy and communication between social groups. They identified objects used in cooperation and knowledge sharing across epistemic boundaries as including repositories such as the library; ideal types such as a species rather than a specimen; co-incident boundaries such as the outline of a map that can have different content; and standardized forms such as templates given to amateurs in the museum to enable standardized methods in distributed work.

Inspired by the idea of 'boundary objects', work on socio-material practices has been further developed in the literature on organization and management in areas such as engineering and design. The term has been used across a variety of empirical contexts, where working processes have different end goals. In the museum setting, the goal is to capture and preserve existing reality; in engineering and design it is create a future reality. Here the focus is prospective rather than retrospective. Early studies were of relatively local situations, such as the cooperation of engineers around printed drawings in a product development department (Henderson 1991, Carlile 2002). More recently, the term has become used to consider how digital objects, such as 3D modelling technologies, are used in coordination that is distributed across sites (Gal, Lyytinen and Yoo 2008, Leonardi and Bailey 2008). Here local material interactions are transformed into distributed interactions: the digital medium makes multiple copies of representations and documents available from keyboards and screens at different remote locations. To enable cooperation across the boundaries of different kinds of expertise, objects must be relatively robust in distributed interactions. At the same time objects such as CAD drawings and plans are the focus of knowledge work and, over time, they may be radically changed through it (Ewenstein and Whyte 2009).

This rich literature on boundary objects provides a vocabulary for analysing the new configurations of digital objects and practices that emerge in project-based work. However, this literature also has some limitations. Engineering and design activities often involve multiple categories of digital objects mobilised across heterogeneous, cross-organizational groups. Yet the focus of the existing literature is on particular objects rather than the connections between different types of objects in practices. It is on informal cooperation and mutual knowledge sharing rather than the more structured forms of coordination that may also arise. Detailed consideration of this literature informs the theoretical question addressed in this analysis.

\section{Boundaries, Objects and Project-Based Work}


Research within the organization and management literature has focused on the boundaryspanning role of a range of objects. In engineering and design settings, these include product models, CAD drawings and plans used to negotiate the product (Henderson 1991, Bechky 2003, Eckert and Boujut 2003, Thomas, Hardy and Sargent 2007, Whyte et al. 2007, Ewenstein and Whyte 2009) and the project charts and project management tools used to negotiate the process (Yakura 2002, Sapsed and Salter 2004). Building on Star and Greisemer, Carlile $(2002,2004)^{2}$ articulated the different categories of objects that become useful at different types of knowledge boundaries in new product development as:

- objects, models and maps - assembly drawings, engineering simulations and other objects used to negotiate the nature of the product and process of its delivery, and their role is to transform data across boundaries;

- standardised forms - indexes and immutable mobiles that allow for standardisation of methods in distributed work processes, and their role is to translate data across boundaries; and

- repositories - piles of catalogued objects as in a library of a museum, or computer aided design (CAD) databases and parts libraries in new product development, and their role is to transfer data across boundaries.

Most studies have focused on the first category without considering standardized forms or repositories or exploring the connections between different types of objects in practices.

This literature has been criticised for rarefying the term 'boundary object' as a descriptor for a wide range of differently structured objects (see Zeiss and Groenewegen 2009). Diversity in the use of the term has lead to conceptual ambiguity and hence a number of discrepant findings. As Trompette and Vink (1999) note: "The notion is sometimes employed in an anecdotal manner to refer to any artefact which is involved in coordination between actors or which is at the boundary of two worlds." Treating the term as a generic description, authors sometimes find objects they study not to be central to coordination. For example, Sapsed and Salter (2004) argue that 'boundary objects' are peripheral to distributed practice, based on their observation that project management tools were relatively unused in a global programme within a major computing organization. From a similar perspective, Levina and Vaast (2005) introduce an additional term 'boundary-objects-in-use' to account for ways in which some objects in their study became useful in coordination, whilst others did not. In contrast, other authors continue to employ 'boundary object' as a more conceptual term, emphasising the constant work required to establish and sustain the boundary-spanning role of objects in engineering and design contexts. As new Geographic Information System (GIS) technologies are introduced, Harvey and Chrisman (1998) describe an ongoing active process through which different social interests are mediated. Chrisman argues that: "Before a boundary object is recognized, each side might think that their terminology was universally understood. Once the negotiation is complete, there are new steps to make adjustments for the differences in meaning" (Chrisman 1999). From this latter perspective there is nothing predetermined about the output, and it may involve new practices.

Informal cooperation and mutual knowledge sharing is emphasized in the literature. Henderson (1991) sees the flexible range of visual representations developed and used by engineers as providing a means for coordination, contrasting this with the imposition of CAD system which is both less flexible and assumes linear working methods. She describes how, at the time of her study, engineers continued to shield their work from this wider system. Bechky (2003) notes how the boundaries of legitimate interest of different social groups, which she terms occupational jurisdiction, are negotiated around the use of objects. Gal, Lyttinen and Yoo (2009) argue that: "Communities establish and express their social identities by using boundary objects that support and are supported by mutual boundary practices." However, as well as such 
mutual negotiation and adjustment, there can be an encouragement to coordinate work, with formal and informal incentivisation of cooperative behaviours and sanctions for noncooperation. Collins, Evans and Gorman $(2007)^{3}$ draw attention to the potential for different levels of collaboration and coerciveness; and different levels of homogeneity and heterogeneity in coordination across knowledge boundaries. Within firms and projects, members have roles and responsibilities and are accountable for the delivery of work, thus coordination is negotiated in the context of wider organizational goals and it may take more structured forms.

In project-based work, organizing involves a changing set of stakeholders over the life of the project; with formal methods for disciplining information across the large set of stakeholders involved at any point in time. To address limitations in the existing literature, this paper examines the first time that an extranet (called Repository) was used in a major civil engineering project. The research question is: how are digital objects used in the coordination of distributed project-based work involving multiple stakeholders? Hence the study interrogates the nature of coordination in a large project involving multiple firms, the nature of the digital objects and their inter-relationships.

\section{Case and Method}

The specific case that we focus on is a large infrastructure project, involving multiple organizations including two engineering design firms engaged to deliver the design. The project provides a new motorway around a major city in a European country. It was selected for study as it pioneered the use of digital technologies for the integration of design data on large projects. The focus is of the study is on learning from the introduction of the extranet, Repository ${ }^{4}$, and its associated standardised forms.

The physical nature of construction work makes it an interesting case in which issues of time, space and resource cannot be avoided. The motorway is more than 40km long with 57 new bridges and work to 20 existing bridges. The project cost about $£ 485$ million and was financed through public and private investment. It was built for a government agency, by a company with responsibility for the full life-cycle of the highway through a Design, Build, Finance, Operate (DBFO) contract. They acted as the client for the design and build joint venture and the design partnerships joint venture. The concept for the road was discussed in 1980 and the large engineering firm (described here as 'Design34') had acted as engineering advisors directly to the client from 1990, after the preferred route was announced. They were involved in the scheme through the second of two public inquiries in the mid 1990s and the legal challenge in the late 1990s.

In this paper we focus on their work during the detail design and construction phase (20002004), when the project was divided into 4 sections, with an engineering firm 'Design12' responsible for the northern half (Sections 1 and 2); and the firm Design34 completing the southern half (Sections 3 and 4). At this stage the project involved more than 600 designers across 20 different locations, and within Design34 alone, about 400 staff from 15 offices worldwide worked on this project. A different construction contractor is involved in each of the 4 sections. Figure 1 provides an overall organizational chart.

\section{$<<$ Insert Figure 1 about here>>}

The availability and use of digital technologies changed significantly over the 15 year period that the project was in development. From a simple set of database, word-processing and spreadsheet tools at the public inquiry stages; the team moved to a more sophisticated set of 
technologies for design, coordination and governance at the detail design stage. The main features of the digital systems at this stage were: a) a central repository for data (Repository), used by all stakeholders associated with the design and build joint venture; and b) firm-specific CAD software used in the design firms. It was the use of these technologies that were the focus of our empirical work.

Case study research provides a way to develop empirically-grounded theory. While our study follows the broad tenets set out in the classic texts on case study research by Eisenhardt (1989, revisited in Eisenhardt and Graebner 2007) and Yin (1994) our approach is more interpretative in nature. This study uses written responses; face-to-face interviews; trade press articles and archival research within an internal corporate database (in Design34) to understand the role of objects in design, project management, coordination and governance over the life of an motorway project. Because of our close working relationship with managers at Design34, we had extra-ordinary access to their internal documents and presentations, at first through time spent collocated in their offices and later through external access to the engineering design firm extranet. We had access to archival information about the project and people; and direct access to key internal documents, such as lessons learnt documents from the project.

Following initial set-up meetings with Design34 and a two-hour set-up meeting with two key stakeholders from Design34 that worked on the project, we identified key participants in the project, sent out pre-interview questionnaires to them and conducted eight semi-structured interviews. We took detailed notes at interviews and went back to our participants to check our understandings from our interview notes. We also taped and transcribed the interviews, using both the transcription and the audio file during our analysis. Most of these interviews were with managers from the engineering firm Design34; but two were with senior managers within the other engineering firm involved in design work on the project (Design12), one of whom had acted as the design manager of the design and build joint venture. Through the interviews we sought to understand the technologies used and the practices involved in the engineering design work. We aimed to get as much contextual data as possible to be sensitive to the wider organizational environment in the analysis (Pettigrew 1985, Pettigrew, Woodman and Cameron 2001).

This case study is the third of six major projects studied as part of a wider trajectory of research on technology strategies and practices in complex project-based settings. The protocol for the data collection draws strongly on the findings of the previous work, and there was an explicit attempt to use an interview protocol to ask questions about the same topics across cases to enable us to compare and contrast practices across this project and the following two cases, which were part of the same research project and accessed through Design34. For each case, data analysis and interpretation started through the preparation of a narrative case report for managers in Design34 and a discussion of this with them. Coding the data and testing codes was used as a process rather than an outcome of the work, it provided a way to familiarise ourselves with the data and to discuss interpretations of the data-set.

While this paper focuses on a single case, in analysing the data we have drawn on our insights from the other cases conducted with Design34 to test our interpretations of this case and emerging theoretical constructs and to assess the generalizability of our findings. As well as feeding back preliminary findings of the individual cases to Design34, we prepared a narrative report on our cross-case analyses and discussed this with Directors from Design34. This informed the further analysis and interpretation of the data in the case discussed here.

\section{Data Analysis: Multiple Knowledge Boundaries and the Coordination Challenge}


The data suggest that introduction of a digital repository and its standardised forms into this major construction project provided a digital infrastructure for project delivery, altering boundaries between firms and their social relations by making approved drawings instantly visible across the project, and by providing an archive of these drawings. Champions see it as a first step in a wider integration of data across the project.

The multiple knowledge boundaries and significant coordination challenges associated with the design and construction of physical infrastructure are highlighted by one of the section leaders. He notes how the 'art of highway engineering' on a large and organizationally-complex project requires engineers and managers to pay serious attention to coordination and knowledge integration:

That's the art of highway engineering really, getting the bridge, the geotechnics and the environmental and everything to work together. It's not just about sticking some black stuff on the ground, that's for sure. (section team leader 3)

As new knowledge is developed, there is a need to coordinate at the interfaces between disciplines - 'the bridge, the geotechnics'; and to coordinate and resolve inconsistencies in the translation of professional knowledge onto site. Such differentiation and integration of tasks is a major concern of organizational theory (Lawrence and Lorsch 1967, Dougherty 2001). Our analyses show how digital objects, the repository and its standardised forms, become enrolled in addressing this, especially in attempts to manage the resultant inter-dependencies.

However, it is important to start by noting that coordination was a major concern on the project studied before the introduction of these digital tools and considerable care was taken over organizational design on the project. Work arrangements were developed by managers in the first six months of the project. By splitting most tasks up spatially they sought to avoid interfaces between the design firms, which have different cultures and procedures. They divided the highway into four overall sections with Design 12 responsible for design of the two northern sections and their packages of work, and Design34 for the two southern sections and their packages. This division of the work into self-contained tasks reduces the overall information processing requirements (Galbraith, 1973). One manager explained:

we did a lot of the coordination, well parts of it was clear boundaries and clear understanding of ownership and clarity of who was doing what in terms of packages of work. (section team leader 2)

The managers, who came from the design partnerships joint venture (Design12 and Design34) and the design and build joint venture, kept the design of a number of small specialist packages of work and repeated components together across the sections. Hence, responsibility for specialist work such as communications was retained within the same team. Bridges were designed in batches which kept work on similar bridges together, with some bridge types designed by Design12, others done by Design34 and still others done by subcontractors. As these batches did not match section boundaries, this created other organizational interfaces that needed management attention:

so that created more interfaces obviously and those are where you have to concentrate your management effort to make sure that the right people are talking to the right other people and transfer the right information. (section team leader 3)

The result is a complex matrix of roles and responsibilities leading to multiple interactions between engineers, technicians, managers and contractors within design firms and across firms. Four significant areas in which there are knowledge boundaries are:

1. Within the design firm (between offices, disciplines, teams and roles);

2. Between the two design firms (Design12 and Design34), this occurs between sections 2 and 3 and around components and specialist work; 
3. Between the design teams and contractors (e.g. between firm Design12 and Contractor1 on section 1); and

4. Between the design teams and the client design advisor.

Digital objects were used in coordination and control across these boundaries. Initially a bespoke database was used to log all drawings and documents, but with the introduction of Repository as a shared online database in 2000, this became the main way in which knowledge work was standardised, integrated and approved across these boundaries. It was championed by Design34, based on a solution that had been developed internally by them and was later commercialised. It was introduced by the design and build joint venture. Tracking the use of this repository across these boundaries draws attention to distributed sets of practices. In the following sub-sections particular examples are used to explore the role of Repository in the integration of design data, work-flow management; knowledge approval and accountability.

\section{Integration of the Design Data within and across Firms}

The digital infrastructure changed the visibility of information across firm boundaries. An example of this is the rainfall data. On the construction site there was an issue with rain. It had been raining heavily and given the geology of the area this was turning ponds orange in a neighbouring golf club that was about to host a major competition. To design temporary holding ponds, an engineer seconded from Design34 to Construction3 had to know how much it rained. She knew that Design34 had used this information in their design work, but as they had purchased the information as a firm they could not release the data to other firms working on the project. The license that they had meant that if other firms, such as Construction3 and DBFO, wanted this raw data then they would need to purchase it separately. While this is normal practice, the integration of the design data through Repository strengthened the sense of the project being the relevant organizational level for such a purchase. Access to a project-wide data-set made this project-level more visible in engineers' day to day work.

At the same time that the digital infrastructure was reinforcing the sense of the project as the relevant organizational level, design work within the firm was becoming more widely distributed across offices. For example to achieve bridge design to project timescales, without having to take staff on short term contracts, Design34 had twenty offices from around the globe working on the project at one stage. Across national boundaries, data was transferred using other systems, not part of Repository, but there were problems as the digital systems were not good enough to enable different offices to work on live data:

\footnotetext{
We had three teams in Australia working on the job and whilst the [Design34] network was good, at the time it wasn't good enough to work on live data that was sitting here when you are sitting in Brisbane doing the work. So again we had the issue of packaging up a set of models on a particular day, sending them off to Australia for them to develop and then getting out of sync with each other and all the rest of it. (project manager)
}

Within an office, coordination was easier and involved shared server space (on an area of the server that was accessible to anyone within the main Design34 office, which was called "internal issues") and through shared models:

We would just share the models because we were working on the same platform, [CADroads] and [CADbasic]; we would make sure we both got the most up-to-date models for the tie-ins. (designer, section 4)

There were some other processes during the design stage that took place outside of the Repository system, which held the final drawings in a non editable format. During design work across the interfaces between the design firms and contractors identified earlier in the paper, there was some transfer of live CAD models. However: 
When we were sending the design out to the contractor we had to convert the design to something the contractor could understand so that was an extra process we had to go through rather than just producing drawings. (engineer, champion for Repository)

A set of standard CAD formats was specified in the contract, however Design34 continued to use a different set of CAD packages internally and they took responsibility for the transfer of data into standard formats when co-ordinating work with Design12 and delivering work for approval. The fact that the two design teams had internal processes and skill-sets in different packages led to difficulties in sharing models in ongoing design work.

It wouldn't have been so much of an issue if we had all been in one office, on one network, in one CAD system. But, [Design12] are designing some of the bridges, [...] within the geographic area we were looking at so you have then got quite a difficult process of managing them because you have multiple copies of data, in different offices geographically, in different CAD systems [...] We didn't really have the technology at the time to manage, call it model management, its management of the data as it's developing through the design process as opposed to the output. (project manager)

The bridges were a particular area of difficulty that involved the design teams and contractors in negotiations on ongoing design work and there were one or two bridges where this went wrong and the bridge had to be knocked down and rebuilt as a result. Such examples were used by the champions as reasons to extend the Repository to hold live design data as well as output files.

\section{Workflow Management through a Digital Infrastructure}

The case was an early public private partnership and the complex organizational arrangements for the delivery of the motorway meant that 'a complex mix of people' needed to approve drawings before construction. While the shared goals of the museum described in Star and Griesemer (1989)'s work was 'preservation', here, the underlying driver was efficient delivery, compliant with standards and requirements. The design validation process was facilitated by Repository:

But if we relied on circulation of bits of paper that would have been a very difficult process so we managed to get a balance in that we had an extranet system set up. Everybody accepted a sort of simple workload process where initially internally we would issue a drawing to our discipline leader so that the leaders of bridges, the leaders of roads, geotechnics, everybody with different disciplines would get sight of the drawing before it went outdoors so it gives people the opportunity to shout if there is an issue between the different discipline interfaces and then it goes to the contractor and he signs that off. So we managed to get that working electronically. (project manager)

Together the repository, standardised forms and drawings form a digital infrastructure for delivery. The key characteristic of this infrastructure is that it made approved information instantly accessible across the project. The digital infrastructure was not primarily used for local cooperation and knowledge sharing but was used to structure distributed forms of coordination and control necessary to accomplish the work in this complex organizational context. It was used for approval of finished work and it is 'inflexible' in that it dictated a set of working practices and processes. Its introduction required large changes in practice and made information accessible to all the relevant parties. It was resisted by engineers within various firms but through training and coaxing it became used, valued and commended:

It was fairly new in the industry, everybody was familiar with emails and all the rest of it but this was a slightly new way of working for a lot of the people involved and we put a lot of effort into developing it and then training people in its use [...] when we first introduced the thing people were very critical, weren't keen to 'buy into' it. It was the worst thing since sliced bread. By the end of the project people were saying 'How could we have done this without [Repository]?' (Design and build joint venture manager)

I suppose the biggest thing was Repository, you know the documents were coming out to everybody through Repository so we had access to them, the client had access to them, the contractor had access to them, everybody had access to the documents and you could tell which was the up to date one. [...] So, 
that was a good system really [...] it meant that all the documents were instantly distributed to everybody who needed to see them and you could see what had been issued for construction because in theory the contractor couldn't start work until the drawings had been issued for construction. (Design34 site team)

Repository made visible knowledge about the audit trail of design deliverables and where the project was in the review process. It managed the workflow approval process, it overcame the version control problem, enabled digital global information sharing and preserved final design knowledge (as protection against claims and as evidence in disputes).

However, it is common for knowledge to be lost in construction as learning often fails to be transferred from project to project. The design of work within the temporary organizations that deliver construction projects is particularly difficult, and political, as they often involve public and private sectors; and organizations within the networks may have different interests and goals. The Repository tool used on the project was later commercialised, and a champion from the project explained their frustration that:

the lessons that we learnt on [this project] haven't got into that piece of software so the approval work flow which was absolutely key to making it work, is still being shouted for and we are still saying 'That's what we desperately need' on projects. (engineer, champion for Repository)

As a repository, used for work-flow management and to make visible outputs, this tool is significantly different from the kind of project management tools and models that have been discussed more extensively in the 'boundary object' literature. These approval workflow characteristics were seen as crucial to its success, however, as discussed in the next section, on the project this success was bounded as new actors needed to be enrolled.

\title{
Knowledge Approval by the Client Advisor and Accountability
}

The client advisor had to review and sign-off work on behalf of the client, DBFO. They had real problems with Repository to start with, although training through the 'train the trainer sessions' helped enrol them into the process. In getting the client advisor to work in a digital manner, the potential for the software to be customised in simple ways, such as changing the terminology used at the user-interface was important. There is a contractual difference between approving and receiving drawings:

\begin{abstract}
So bits of all these other contracts that exist above us flow down and everyone is expected to line up and be compatible with. So, it is very useful to have a bit of software that receives instead of approves because otherwise the guy who you are sending it to will refuse to press the button because it says approved and he isn't going to approve. But we wanted [Client's advisors] to press the button. We wanted them to participate in this system so it was important it was using their terminology. (section team leader 4)

They had to approve the design or I think, nobody likes to use the word approve, do they? They had a choice of responding; received, received with comments or returned. (Design and build joint venture manager)
\end{abstract}

Because of the role of the digital objects in accountability, this subtle change was important in enabling the use of the digital infrastructure in this wider approval process. Design34 was keen to make all knowledge approval processes electronic, and they succeeded in making the stages within the design firm and the link with the construction firms fully electronic, but the client design advisor still required paper copies for signature.

The [client advisor] never accepted it as the final sign-off but they did work with it as a day to day system so what we used to do was use the system electronically but then every month get together, a meeting with a big pile of papers and certificates where everybody would go through a crazy process of signing pieces of paper. (project manager)

Although this question of accountability was resolved, the staff in the client advisor continued to find it difficult to access drawings and documents and it was eventually discovered by the 
champions in Design34 that they only had one computer and one 56k modem link, which was causing a bottle-neck in the digital process.

As an archive, the repository became a record of decisions that were made. To reject a drawing, the reviewer had to input the rationale for his or her decision. This made these judgements more widely visible to the appropriate parties within the project:

\begin{abstract}
Maybe one of our drawings has been rejected by the approvals authority - the rejection and all the background reasons to the rejection are all typed in onto forms on the [Repository] system so if I wanted to see what somebody had said and what the logic was then I would go into that system to look (project manager)
\end{abstract}

Repository was used very actively for many years post project-completion and its hosting was still being paid for by the design and build joint venture at the time of data collection in 2008. It is not used to merely preserve the past but rather continues to shape the present. Beyond the project close, when the parties are no longer actively engaged in work on the project, the repository of signed-off drawings has been used as evidence in claims and disputes.

\title{
Discussion: Developing the Digital to Deliver the Physical
}

The findings show digital objects becoming used in the integration of design data within and across firms, in work-flow management and in knowledge approval towards the goal of efficient delivery of physical infrastructure compliant with standards and regulations. Although the literatures on boundary objects in design and engineering have tended to treat categories of objects as separate, this analysis indicates that 'objects, models, maps', standardised forms and repositories are better conceptualized as the same thing, a digital infrastructure.

This digital infrastructure is used for the delivery of physical infrastructure. This term 'digital infrastructure' draws attention to the nested sets of objects associated with coordination of knowledge across multiple knowledge boundaries in the delivery of projects. Standardised forms are integral to the use of repositories, which are populated with sets of maps, models and other documents. As work has become more radically distributed, across firms, offices, disciplines, teams and roles this infrastructure appear more tightly coupled, with a centralization and formalization of work methods and objects that reduces discretion. By changing local material interactions into distributed interactions the digital medium made this infrastructure for delivery possible. It is central to the coordination of work across different knowledge bases and levels of expertise in the case studied.

This coordination involves accountability and control as well as cooperation and knowledge sharing. Though Henderson (1991) finds engineers collaborating informally, and struggling to work around the prescribed new technology that is introduced by management, this is not the main finding here. In the case studied, work is highly disciplined, with digital tools and methods integrated into working processes. The various design teams operate in a commercial environment, in which the tool Repository holds the drawings and documents used for the project and its use is prescribed through standard protocols and procedures. With design work taking place across firms in a public private partnership, some aspects of the interactions and interdependencies are prescribed through contractual obligations, labour contracts, standards, procedures and workflow processes. The digital infrastructure is used in controlled and managerial forms of coordination, such as version control, approvals and sign-off.

Such organizing involves sets of hierarchical as well as lateral relationships, relationships with clients and regulators as well as relationships with fellow engineers. As Clegg argues "Organization means control" (Clegg 1989: p. 102). Managers on the project have legitimate interests in ensuring that the 'right people are talking to the right other people and transfer the 
right information.' Here the project set-up to reduce the significant effort required for integration through coordinative practices, with boundaries designed to reduce the amount of coordination required in ongoing operations. The implementation of a digital infrastructure for delivery is part of this process of designing methods and objects to meet organizational goals. However, as the interaction with the client advisor in this case shows, control is never total, but rather boundaries, methods, objects and goals are negotiated. Among the multiple stakeholders to the project, different actors have different abilities to take control or refuse to participate (ErikssonZetterquist, Lindberg and Styhre 2009). While the champions of the Repository strive for further integration of working practices, the set-up on the project gave autonomy to engineers within Design34 to work using their established work methods within the firm, translating objects to deliver work in prescribed formats and to coordinate with the wider project.

The introduction of Repository as a new tool changes the organization and methods of project work as it changes the visibility of information. There is a workflow process by which drawings get issued to a discipline leader then across disciplines and then across firms. Drawings, and their status, thus become more widely visible across the project, and in this process 'everybody with different disciplines would get sight of the drawing' and they become accountable for any uncoordinated areas of work as they 'have a chance to shout.' By shaping work practices this infrastructure thus provides new roles (Georg and Tryggestad 2009) and new 'rules of the game' (Clegg, 1989) that enables and constrains action. These changes have implications for identity of engineers, as well as their work, and in this case add to the identification with the project-level as a relevant organizational level.

The term 'infrastructure' is often used to describe systems at a very large scale: "it connotes big, durable, well-functioning systems and services, from railroads and highways to telephone, electric power, and the Internet" (Edwards et al. 2009: p. 365). Like physical infrastructure, which is built through projects such as the motorway project studied here, digital infrastructure for delivery is not completed in one go, but rather is developed through work on particular projects and through drawing connections across projects. Thus the Repository champions have plans to use the increasing maturity of digital systems to enhance coordination on future problems and 'fix' problems that arose on the projects, such as the need for new work practices in transferring data between incompatible systems; and the need for work to be packaged up and sent out to remote offices rather than worked on in a 'live' system.

Use of the term 'digital infrastructure' links the rich work on boundary objects in design and engineering with a set of work on creating infrastructure. It provides an opportunity to enrich the discussion of boundary objects in the literature on organization and management as connections between categories of objects became increasingly important in the later work by Star and her colleagues. Hence, both trajectories of work emerge out of the same debates that coined the 'boundary object' term, with the emergent field of infrastructure studies focusing first on information of both digital and physical nature (Bowker and Star 1999) and then on global networks for science or information infrastructure (Edwards et al. 2007); with more recent work on organizational IT (Pipek and Wulf 2009). Bowker and Star (1999), for example, describe information infrastructure as combining a classification or taxonomy of the objects being recorded (similar to the repository and its standardised forms discussed above); and also the set of diverse objects that establishes a shared syntax or language for individuals to represent their knowledge (similar to the objects, models and maps).

\section{Conclusions and Implications}

Based on this empirically grounded analysis of the use of objects in the coordination of projectbased work, existing theory is extended in two main ways: 
First, by showing how digital objects provide mechanisms for accountability and control, as well as for mutual and reciprocal knowledge sharing. Coordination processes were highly structured as knowledge boundaries involved different offices, disciplines, teams and roles (as discussed in the previous literature) but also multiple firms (in this case between design firms, between design teams and contractors, and between design teams and the client design advisor). The cross-organizational nature of these latter boundaries required a set of contractual and organizational arrangements that, at times, constrain mutual knowledge sharing.

Second, by articulating how these digital objects are nested and form a digital infrastructure for project delivery. The increasing maturity of digital systems led to work being distributed across global offices, however the form of organizing that results involves prescribed processes, stagegates and top-down, hierarchical forms of sign-off and control rather than networks with distributed non-hierarchical, relational forms of organizing.

The idea of digital infrastructure provides a starting point for further research into the changing nature of digitally-enabled coordination in project-based work. This work is needed to understand how the 'virtual world' is involved in different socio-material practices; the scale and reach of integrated software solutions, such as building information models, the purposes that they serve in across different local practices, and in particular how their role in coordination, both through cooperation and through more controlled and managerial approaches, coexists with their roles in individual knowledge work.

Such detailed unpacking of the categories of objects used in engineering work may seem mundane. A revisiting of the everyday tools and practices that are involved in work is unlikely to provide prescriptive advice. However, it can provide practitioners with important material to use in reflectively improve their practices. In setting out to achieve their longer term goals, the idea of digital infrastructure suggests that practitioners need to be aware that implementation of digital tools, such as extranets and building information models, changes the boundaries between firms, offices, disciplines, teams and roles. It shapes social relations as it develops new practices and changes the visibility of information. The idea of digital tools as 'infrastructure' suggests that changes take time. In the case of Repository, the management of the outputs of design became an antecedent to the broader management of data as its developing through the design process. The case suggests that it is useful for implementers to think of projects as an opportunity to design, build and test new processes, but rather than a whole infrastructure being fully designed and implemented within a single project, sets of objects will often be incrementally improved and elaborated across a number of projects.

\section{References}

Bechky, B A (2003) Object lessons: Workplace artifacts as representations of occupational jurisdiction. American Journal of Sociology, 109(3), 720-52.

Blackler, F and Engeström, Y (2005) Special issue on the rise of objects in the study of organizations. Organization, 12(3).

Boland, R J, Lyytinen, K and Yoo, Y (2007) Wakes of innovation in project networks: The case of digital 3-D representations in architecture, engineering, and construction. Organization Science, 18(4), 631-47.

Bowker, G and Star, S L (1999) Sorting Things Out. Cambridge, MA: MIT Press.

Cacciatori, E (2008) Memory objects in project environments: Storing, retrieving and adapting learning in project-based firms. Research Policy, 37(9), 1591-601.

Carlile, P R (2002) A pragmatic view of knowledge and boundaries: Boundary objects in new product development. Organization Science, 13(4), 442-55. 
Carlile, P R (2004) Transferring, translating and transforming: An integrative relational approach to sharing and assessing knowledge across boundaries. Organization Science, 15(5), 555-68.

Chrisman, N (1999) Trading Zones or Boundary Objects: Understanding Incomplete Translations of Technical Expertise, $4 S$ - Society for the Social Studies of Science, October 28th-31st, San Diego CA.

Clegg, S (1989) Radical revisions: Power, discipline and organizations, Organization Studies, 10(1), 97-115.

Collins H, Evans R and Gorman M (2007) Trading zones and interactional expertise, Studies In History and Philosophy of Science, 38(4), 657-66.

D’Adderio, L (2003) Configuring software, reconfiguring memories: The influence of integrated systems on the reproduction of knowledge and routines. Industrial and Corporate Change, 12(2), 321-50.

Dougherty, D (2001) Reimagining the differentiation and integration of work for sustained product innovation. Organization Science, 12(5), 612-31.

Eckert, C and Boujut, J-F (2003) The role of objects in design co-operation: Communication through physical or virtual objects. Computer Supported Cooperative Work, 12(2), 14551.

Edwards, P N, Jackson, S J, Bowker, G C and Knobel, C P (2007) Understanding Infrastructure: Dynamics, tensions, and design. Ann Arbor, MI: DeepBlue.

Edwards, P N, Bowker, G C, Jackson, S J and Williams, R (2009) Introduction: An agenda for infrastructure studies. Journal of the Association for Information Systems, 10(5), 364-74.

Eisenhardt, K M (1989) Building theories from case study research. Academy of Management Review, 14(4), 532-50.

Eisenhardt, K M and Graebner, M E (2007) Theory building from cases: Opportunities and challenges. Academy of Management Journal, 50(1), 25-32.

Erdogan, B, Anumba, C J, Bouchlaghem, N M and Nielsen, Y (2008) Collaboration environments for construction: Implementation case studies. ASCE Journal of Management in Engineering, 24(4), 234-44.

Eriksson-Zetterquist, U, Lindberg, K and Styhre, A (2009) When the good times are over: Professionals encountering new technology. Human Relations, 62(8), 1145-70.

Ewenstein, B and Whyte, J (2009) Knowledge practices in design: The role of visual representations as 'epistemic objects'. Organization Studies, 30(1), 7-30.

Fischer, $\mathrm{M}$ and Drogemuller, R (2009) Virtual design and construction. In: Newton, P, Hampson, $\mathrm{K}$ and Drogemuller, R (Eds.), Technology, Design and Process Innovation in the Built Environment, pp. 293-318. Abingdon, UK: Taylor and Francis.

Forgues, D, Koskela, L and Lejeune, A (2009) Information technology as boundary object for transformational learning. Journal of Information Technology in Construction, 14, 48-58.

Gal, U, Lyytinen, K and Yoo Y (2008) The dynamics of IT boundary objects, information infrastructures, and organisational identities: the introduction of 3D modelling technologies into the architecture, engineering, and construction industry, European Journal of Information Systems, 17(3), 290-304.

Galison, P (1996) Computer simulations and the trading zone. In: Galison, P and Stump, D J (Eds.), The Disunity of Science. Stanford: Stanford University Press.

Georg, S and Tryggestad, K (2009) On the emergence of roles in construction: The qualculative role of project management Construction Management and Economics, 27(10), 969-81.

Gherardi, S and Nicolini, D (2000) To transfer is to transform: The circulation of safety knowledge. Organization, 7(2), 329-48.

Harty, C (2005) Innovation in construction: A sociology of technology approach. Building Research and Information, 33(6), 512-22. 
Harvey F and Chrisman N (1998) Boundary objects and the social construction of GIS technology, Environment and Planning A, 30(9), 1683-94.

Henderson, K (1991) Flexible sketches and inflexible data bases: Visual communication, conscription devices, and boundary objects in design engineering. Science, Technology and Human Values, 16(4), 448-73.

Jarzabkowski, P and Seidl, D (2008) The role of meetings in the social practice of strategy. Organization Studies, 29(11), 1391-426.

Knorr Cetina, K (1999) Epistemic Cultures: How the sciences make knowledge. Cambridge, MA: Harvard University Press.

Lawrence, P R and Lorsch, J W (1967) Differentiation and integration in complex organizations. Administrative Science Quarterly, 12(1), 1-30.

Leonardi, P M and Bailey, D E (2008) Transformational technologies and the creation of new work practices: Making implicit knowledge explicit in task-based offshoring. MIS Quarterly, 32(2), 411-36.

Levina, $\mathrm{N}$ and Vaast, E (2005) The emergence of boundary spanning competence in practice: Implications for the implementation and use of information systems. MIS Quarterly, 29(2), 335-63.

Orlikowski, W J (2007) Sociomaterial practices: Exploring technology at work. Organization Studies, 28(9), 1435-48.

Pettigrew, A M (1985) Contextualist research and the study of organizational change process. In: Mumford, E, Hirschheim, R, Fitzgerald, G and Wood-Harper, A T (Eds.), Research Methods in Information Systems, pp. 53-78. Oxford, UK: New Holland.

Pettigrew, A M, Woodman, R W and Cameron, K S (2001) Studying organizational change and development: Challenges for future research. Academy of Management Journal, 44(4), 697-713.

Pipek, V and Wulf, V (2009) Infrastructuring: Toward an integrated perspective on the design and use of information technology. Journal of the Association for Information Systems, 10(5), 447-73.

Rheinberger, H-J (1997) Toward a History of Epistemic Things: Synthesizing proteins in the test tube. Stanford, CA: Stanford University Press.

Sapsed, J and Salter, A J (2004) Postcards from the edge: Local communities, global programs and boundary objects. Organization Studies, 25(9), 1515-34.

Shen, G, Brandon, P and Baldwin, A (Eds.) (2009) Collaborative Construction Information Management. London, UK: Spon.

Star, S L and Griesemer, J R (1989) Institutional ecology, 'translations', and boundary objects: Amateurs and professionals in Berkeley's museum of vertebrate zoology, 1907 - 1939. Social Studies of Science, 19(3), 387-420.

Taylor, J E (2007) Antecedents of successful three-dimensional computer-aided design implementation in design and construction networks. Journal of Construction Engineering \& Management, 133(12), 993-1002.

Thomas, R, Hardy, C and Sargent, L (2007) Artifacts in Interaction: The production and politics of boundary objects, Advanced Institute of Management (AIM) Research Paper 052, London, UK: AIM.

Trompette P and Vinck D (2009) Revisiting the notion of boundary object, Revue d'Anthropologie des Connaissances, 3(1), 3-25.

Van Marrewijk, A, Clegg, S R, Pitsis, T S and Veenswijk, M (2008) Managing public-private megaprojects: Paradoxes, complexity, and project design. International Journal of Project Management, 26(6), 591-600.

Whyte, J K, Ewenstein, B, Hales, M and Tidd, J (2007) Visual practices, and the objects of design. Building Research and Information, 35(1), 18-27. 
Yakura, E K (2002) Charting time: Timelines as temporary boundary objects. Academy of Management Journal, 45(5), 956-70.

Yin, R K (1994) Case Study Research: Design and methods. Thousand Oaks, CA: Sage.

Zeiss, R and Groenewegen, P (2009) Engaging boundary objects in OMS and STS? Exploring the subtleties of layered engagement. Organization, 16(1), 81-100. 


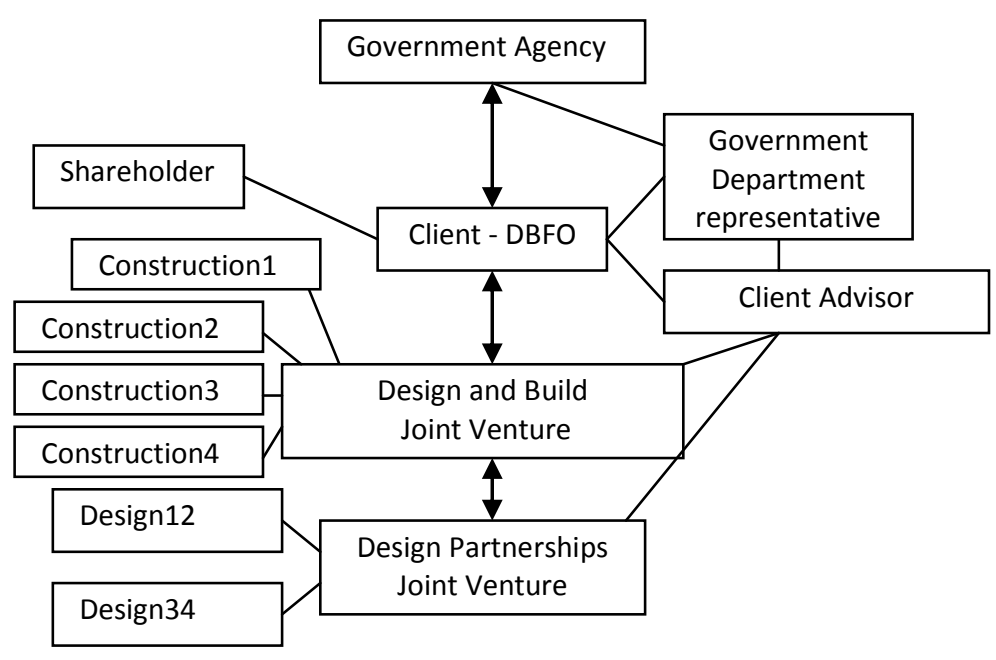

Figure 1: Organizational chart of the project in the detail design and construction phase adapted from source document 
${ }^{2}$ For examples see the special issue (Blackler and Engeström 2005) and also work on the related functions of objects as epistemic objects (Rheinberger 1997, Knorr Cetina 1999, Ewenstein and Whyte 2009) and memory objects (D'Adderio 2003, Cacciatori 2008)

${ }^{2}$ Carlile's category of 'objects, models and maps' draws together two types of boundary objects identified by Star and Griesemer in the museum context: ideal types - abstracted diagram, atlas or other description (e.g. species which does not describe any one specimen) and co-incident boundaries - objects that have same boundaries different internal contents (e.g. State of California). This reformulation significantly changes the focus. Within the classification, there is also a recursive (and hence confusing) use of the term 'objects' as a sub-category of the class of 'objects'.

${ }^{3}$ Collins, Evans and Gorman (2007) draw on Galison's (1996) idea of a 'trading zone', which is similar to the idea of a 'boundary object' but requires the emergence of a new language for coordination to develop (Chrisman 1999). Levina and Vaast (2005) similarly argue that for boundary spanning to emerge a new joint field of practice must be produced. In the main 'boundary object' literature, however, through the negotiation process there may simply be awareness that other epistemic groups attach different meanings.

${ }^{4}$ The term 'repository' will continue to be used in the general sense, with a capitalization in the pseudonym 'Repository', used in reference to the particular software used on this project. 